1

2

3

4

5

6

7

8 Marta S. Pimentel1,2*, Filipa Faleiro, Tiago Marques ${ }^{3,4}$, Regina Bispo ${ }^{4,5}$, Gisela

9 Dionísio ${ }^{1,6}$, Ana M. Faria ${ }^{5}$, Jorge Machado², Myron A. Peck ${ }^{7}$, Hans Pörtner ${ }^{8}$, Pedro 10

11

12

13

14

15

16

17

18

19

20

21

22

23

24

25

26

27

28

29

30

31

32

*Corresponding author (Marta Pimentel: mcrsilva@fc.ul.pt)

\section{Foraging behaviour, swimming performance and malformations of early stages of commercially important fishes under ocean acidification and warming}

Pousão-Ferreira ${ }^{9}$, Emanuel J. Gonçalves ${ }^{5}$, Rui Rosa ${ }^{1}$

${ }^{1}$ MARE - Marine and Environmental Sciences Centre, Faculdade de Ciências da Universidade de Lisboa, Laboratório Marítimo da Guia, Avenida Nossa Senhora do Cabo 939, 2750-374 Cascais, Portugal.

2 Instituto Ciências Biomédicas Abel Salazar, Universidade do Porto, Largo Prof. Abel Salazar 2, 4099-003 Porto, Portugal.

${ }^{3}$ Centre for Research into Ecological and Environmental Modelling, University of St Andrews, The Observatory, Buchanan Gardens, Fife, KY16 9LZ, UK.

${ }^{4}$ Startfactor, Lda, Taguspark, Núcleo Central 291, 2740-122 Oeiras, Portugal.

5 MARE - Marine and Environmental Sciences Centre, ISPA - Instituto Universitário, Rua Jardim do Tabaco 34, 1149-041 Lisboa, Portugal.

6 Departamento de Biologia \& CESAM, Universidade de Aveiro, Campus Universitário de Santiago, 3810-193 Aveiro, Portugal.

7 Institute for Hydrobiology and Fisheries Science, University of Hamburg, Olbersweg 24, 22767 Hamburg, Germany.

${ }^{8}$ Alfred Wegener Institute for Polar and Marine Research, Animal Ecophysiology, Postfach 120161, 27515 Bremerhaven, Germany.

${ }^{9}$ Instituto Português do Mar e da Atmosfera, Av. 5 de Outubro, 8700-305 Olhão, Portugal. 
34

35

36

37

38

39

40

41

42

43

44

45

46

47

48

49

50

51

52

53

54

55

56

57

58

59

60

61

\section{Abstract}

Early life stages of many marine organisms are being challenged by climate change, but little is known about their capacity to tolerate future ocean conditions. Here we investigated a comprehensive set of biological responses of larvae of two commercially important teleost fishes, Sparus aurata (gilthead seabream) and Argyrosomus regius (meagre), after exposure to future predictions of ocean warming $(+4 \stackrel{\circ}{\circ})$ and acidification $(\Delta \mathrm{pH}=0.5)$. The combined effect of warming and hypercapnia elicited a decrease in the hatching success (by 26.4 and $14.3 \%$ for $S$. aurata and A. regius, respectively) and larval survival (by half) in both species. The length for newly-hatched larvae was not significantly affected, but a significant effect of hypercapnia was found on larval growth. However, while $S$. aurata growth was reduced (24.8-36.4\% lower), A regius growth slightly increased (3.2-12.9\% higher) under such condition. Under acidification, larvae of both species spent less time swimming, and displayed reduced attack and capture rates of prey. The impact of warming on these behavioural traits was opposite but less evident. While not studied in $A$. regius, the incidence of body malformations in $S$. aurata larvae increased significantly (more than tripled) under warmer and hypercapnic conditions. These morphological impairments and behavioural changes are expected to affect larval performance and recruitment success, and further influence the abundance of fish stocks and the population structure of these commercially important fish species. However, given the pace of ocean climate change, it is important not to forget that species may have the opportunity to acclimate and adapt.

Keywords: Ocean climate change, fish early stages, survival and growth, malformations, behaviour, ecophysiology 
63

Atmospheric $\mathrm{CO}_{2}$ levels are rising at an unprecedented rate. The continuous absorption of atmospheric $\mathrm{CO}_{2}$ by oceans is causing a decline in ocean's $\mathrm{pH}$, which is expected to decrease $0.4-0.5$ units by the year 2100. In parallel, sea surface temperature is expected to rise by up to $4{ }^{\circ} \mathrm{C}$ by the end of the century (Collins et al. 2013). Ocean warming and acidification represent a major threat to many marine organisms by affecting their acid-base balance, metabolism, growth and behaviour (Munday et al. 2011; Pörtner et al. 2004) in ways that often compromise species fitness and survival (Wittmann and Pörtner 2013).

Fishes were thought to be quite resilient to exposure to elevated $\mathrm{CO}_{2}$, given their strong ability to regulate acid-base balance by bicarbonate accumulation and ion exchange across the gills (Melzner et al. 2009). Nevertheless, fish early life stages have shown to be more susceptible to elevated $\mathrm{CO}_{2}$ than adult fish (reviewed by Pörtner et al. 2005). Several studies have reported direct effects of elevated $p \mathrm{CO}_{2}$ on survival, growth, metabolism, behaviour, otoliths and skeletal development of marine fish larvae (Baumann et al. 2012; Frommel et al. 2014; Munday et al. 2011; Pimentel et al. 2014). Other studies have found no significant effects of increasing $p \mathrm{CO}_{2}$ on fish larvae (Harvey et al. 2013; Hurst et al. 2013; Maneja et al. 2013b), suggesting species-specific responses to changing ocean conditions.

To date, very few studies have investigated the susceptibility of early stages of commercially important fish species to climate-driven changes, including codfish (Frommel et al. 2014) and yellowfin tuna (Bromhead et al. 2015). Given the importance of larval growth and survival rates to the year-class success in marine fish populations (Peck et al. 2012), deleterious effects of climate-driven changes in $p \mathrm{CO}_{2}$ and temperature may have profound consequences on the distribution and abundance of marine fish stocks (Pörtner and Peck 2010). Here we analysed the effects of ocean warming $\left(+4^{\circ} \mathrm{C}\right)$ and acidification $(\Delta \mathrm{pH}=0.5)$ on the development and behaviour of early life stages of two commercially important fish species in the NE Atlantic Ocean, namely the gilthead seabream Sparus aurata and the meagre Argyrosomus regius.

\section{Methods}


Eggs of $S$. aurata were collected at the hatchery Maresa (Mariscos de Estero, Spain), in November 2013. Eggs of A. regius were obtained from Instituto Português do Mar e da Atmosfera (IPMA) - Centro Regional de Investigação Pesqueira do Sul (CRIPSul, Olhão, Portugal), in May 2014. Meagre eggs were obtained from a wild-caught broodstock of four females and two males. Eggs were collected immediately after spawning and transferred to the aquaculture facilities in Laboratório Marítimo da Guia (Cascais, Portugal). At approximately 5 hours

after spawning, eggs were acclimated to the different experimental conditions.

\section{Egg incubation and larval rearing}

Following an acclimation period of about 2 h, S. aurata and A. regius eggs were exposed to four experimental treatments, a cross-factor design of two temperatures and two $\mathrm{CCO}_{2}$ levels: (1) control temperature and normocapnia $\left(p \mathrm{CO}_{2}=\sim 350 \mu \mathrm{atm}, \mathrm{pH}=8.0\right)$; (2) control temperature and hypercapnia $\left(p \mathrm{CO}_{2}=\sim 1400 \mu \mathrm{atm}, \mathrm{pH}=7.5, \Delta \mathrm{pH}=0.5\right)$; (3) the expected warming scenario $\left(+4{ }^{\circ} \mathrm{C}\right)$ and normocapnia; and (4) warming and hypercapnia. Control temperatures represented the average temperature during the spawning season of $S$. aurata (18 ${ }^{\circ} \mathrm{C}$; Arias 1980) and A. regius $\left(20^{\circ} \mathrm{C}\right.$; Quéro and Vayne 1987).

For each species and treatment, eggs and larvae were reared in 3 independent recirculating systems (12 per species in total), each composed of a 19 L cylindrical rearing tank connected to a $100 \mathrm{~L}$ sump. To ensure an accurate water temperature in each experimental treatment, the rearing tanks were placed inside 400-L water bath tanks. All rearing systems were filled with filtered $(1 \mu \mathrm{m})$ and UV-irradiated seawater (salinity 35). Temperatures were kept stable via seawater chiller systems. pH levels were monitored with glass $\mathrm{pH}$ probes (Schott $囚$ Instruments) connected to a ProfiLux system (GHL, Germany). pH was automatically adjusted via solenoid valves, by injecting a certified $\mathrm{CO}_{2}$ gas mixture into the water or by aerating the water with $\mathrm{CO}_{2}$ filtered air (by using $\mathrm{CO}_{2}$ scrubbers with soda lime). Salinity, temperature and pH levels were also manually monitored daily. Total 
alkalinity was spectrophometrically determined (at 595nm) according to Sarazin et al. (1999). $\mathrm{pH}$ and alkalinity measurements were used for $p \mathrm{CO}_{2}$ calculation (see Supplementary Table 1 for seawater carbonate chemistry), using the CO2SYS program (Lewis and Wallace, 1998), with dissociation constants from Mehrbach et al. (1973) as refitted by Dickson and Millero (1987). Ammonia and nitrites were monitored regularly and maintained within recommended levels.

For the embryonic development experiment, 10 eggs were randomly placed inside a small rearing box in each rearing tank, and followed for approximately 43 hours until hatching. The remaining eggs were distributed in egg-incubation tanks and further used for the larval experiment. After hatching, larvae were carefully counted and transferred to the rearing tanks. S. aurata larvae were randomly distributed at a density of 70 larvae $\mathrm{L}^{-1}$ and reared until 15 days post-hatch (dph). Larvae were fed on rotifers (Brachionus plicatilis) at an increasing density of 5 to 10 rot mL $\mathrm{mL}^{-1}$ between 2 and $15 \mathrm{dph}$, and Artemia nauplii $\left(0.2-2 \mathrm{art} \mathrm{mL}^{-1}\right)$ from 10 to 15 dph [adapted from Fernández et al. (2008)]. A. regius larvae were reared at a density of 45 larvae $\mathrm{L}^{-1}$ for 10 days. Larvae started to feed on rotifers (from 5 to 10 rot mL $\left.\mathrm{m}^{-1}\right)$ between 2 and $10 \mathrm{dph}$, and Artemia nauplii (0.2-2 art mL $\left.\mathrm{m}^{-1}\right)$ was gradually introduced at 6 dph until the end of the experiment [based on Pousão-Ferreira et al. (2013)]. Both rotifers and Artemia nauplii were enriched with Red Pepper. At the end of each day, prey availability in each rearing tank was checked to ensure that prey density was never a limiting factor regardless of the treatment. The light regime in both experiments was $14 \mathrm{~L}: 10 \mathrm{D}$.

\section{Hatching success, survival and growth}

The hatching success and larval survival were determined per rearing tank, based on the number of surviving larvae at hatching and at the end of the experiment, respectively. In each tank, the standard length at hatching and at the end of the experiment (i.e., $15 \mathrm{dph}$ and $10 \mathrm{dph}$ for $S$. aurata and A. regius, respectively) was measured for 4 individuals (12 per treatment) using a dissecting microscope. The somatic length growth (SLG) was calculated as the difference between the mean length at hatching and the length of each larva at the end of the experiment divided by the time elapsed. 


\section{Body malformations}

At the end of the experiment, $20 \mathrm{~S}$. aurata larvae per tank (60 per treatment) were sampled and fixed in $4 \%$ buffered paraformaldehyde for $24 \mathrm{~h}$, and then transferred

to $70 \%$ ethanol. Larvae were observed under a microscope to identify and quantify body structure malformations and/or axial deviations, based on Boglione et al. (2001). Malformations were classified according to the affected area (cranium, abdominal and caudal region). Cranium malformations included asymmetric eye, deformed meckel's cartilage in the jaw and deformed ceratobranchial in the opercle. Abdominal and caudal malformations included abnormal body curvatures such as side-to-side, excessive inward and outward curvatures, and abnormal urostyle flexion. Malformations were quantified as the percentage of fish exhibiting a specific deformity. The incidence of body malformations in A. regius larvae was

\section{Behavioural patterns} 193

Experiments led to data expressed as (1) proportions (hatching success, survival

Behavioural observations of $S$. aurata and A. regius larvae were conducted at the end of both experiments. A preliminary study was performed to establish the ethogram for both species (Table 2). Swimming (S) and spin (Sp) behaviours were recorded as time variables, whereas miss (M), attack (A) and capture (C) behaviours were recorded as frequency variables. The capture success was calculated as the fraction of successful attack events (based on Drost 1987). The behavioural patterns were analysed through direct observation by a "blind observer", using the focal animal technique. Four larvae per rearing tank (12 per treatment) were randomly selected and the behaviour of each larva was analysed inside the rearing tanks during 1 minute, 30 min after feeding.

\section{Statistical analyses} success, and malformations), (2) counts (number of observed behaviours), and (3) 
194 positive quantities (measures of lengths and growths). All data were analysed via 195 generalized linear mixed models (GLMM, e.g. Zuur et al. 2009). The distributional 196 family considered was binomial (logit link function), Poisson (logit link function) 197 and Gaussian (identity link function) for proportions, counts and positive 198 quantities, respectively. Model's residuals were checked for departures from the assumed distributions and no significant deviations were found. The mixed model component was introduced to respect the properties of the experimental design, i.e., box/tank were always included as a random effect to account for possible 202 dependency within tanks. Following the recommendation from Barr et al. (2013), we kept the random effects in the model irrespectively of the amount of variation it explained. All models considered included the same 2-level fixed effects, i.e., temperature and $\mathrm{pH}$, as well as their all second order interaction. For body malformations, behaviour and survival, which response could be conditional on the rearing time, we did not include species as an explanatory variable in the model to avoid confounding between effects by species and rearing time. For variables not dependent on rearing time, we considered species as an additional fixed effect, as well as the corresponding three second order interactions. The most parsimonious models were selected based on Akaike Information Criterion and used for inference. This potentially allowed to borrow strength across species to find significant treatment effects. Odds ratios and confidence limits are also presented for Binomial models, allowing a more informative discussion of the results. Odds were defined as the ratio of the probability of success and the probability of failure, and odds ratios were build by the ratio of odds under control temperature or normocapnia and odds under warming or hypercapnia. All statistical analyses were implemented in R (R Core Team, 2014), using the hglm

\section{Results}

Hatching success and survival

Regarding hatching success (Fig. 1A,B), the most parsimonious model included the 226 main effects of temperature $(\beta=-0.721, \mathrm{SE}=0.272, \mathrm{p}=0.008)$ and $p \mathrm{CO}_{2}(\beta=-0.599$, 
$\mathrm{SE}=0.271, \mathrm{p}=0.027)$. Neither the effect of species $(\mathrm{p}=0.579)$ nor the interaction between both factors $(p=0.981)$ was significant. The odds of hatching under warming were only 0.39 (95\% CI: $0.29,0.76)$ times the odds of hatching under control temperature, i.e., the odds ratio of hatching were approximately 2.6 higher at control temperature. The odds of hatching under hypercapnia were only 0.59 (95\% CI: $0.32,1.15)$ times the odds of hatching under normocapnia i.e., the odds ratio of hatching were approximately 1.69 higher under normocapnia.. Specifically, the hatching success of $S$. aurata decreased from $88.3 \pm 7.6 \%$ in the control to $65.0 \pm 10.0 \%$ in the future scenario, while the hatching success of $A$. regius decreased from $93.3 \pm 5.7 \%$ in the control to $80.0 \pm 10.0 \%$ in the future scenario.

In terms of survival, a model was considered for each species. Regarding S. aurata (Fig. $1 \mathrm{C}$ ), the main effects of temperature $(\beta=-1.237, \mathrm{SE}=0.130, \mathrm{p}<0.001)$ and $p \mathrm{CO}_{2}$ $(\beta=-0.313, S E=0.130, p=0.016)$ were significant, with survival being lower under higher temperature and hypercapnia. The odds of survival under warming were only $0.29(95 \%$ CI: $0.22,0.37)$ times the odds of survival under control temperature, i.e., the odds ratio of survival was approximately 3.5 higher at control temperature. The odds of survival under hypercapnia were 0.73 (95\% CI: 0.57, 0.94) times the odds of survival under normocapnia, i.e., the odds ratio of survival was approximately 1.4 higher at normocapnia. However, the interaction between temperature and $p \mathrm{CO}_{2}$ was not significant $(\mathrm{p}=0.414)$. Survival rates of this species decreased from $43.3 \pm 2.8 \%$ under control conditions to $20.8 \pm 2.9 \%$ under the future scenario. Regarding A. regius (Fig. 1D), the main effects of temperature $(\beta=-$ 1.015, $\mathrm{SE}=0.113, \mathrm{p}<0.001)$ and $\mathrm{CCO}_{2} \quad(\beta=-0.301, \mathrm{SE}=0.113, \mathrm{p}=0.008)$ were significant, but the interaction between them was not $(p=0.236)$. The odds of survival under warming were only $0.36(95 \% \mathrm{CI}: 0.29,0.45)$ times the odds of survival under control temperature, i.e., the odds ratio of survival was 2.8 higher at control temperature. The odds of survival under hypercapnia were 0.74 (95\% CI: $0.59,0.92$ ) times the odds of survival under normocapnia, i.e., the odds ratio of survival was 1.4 higher at normocapnia. The survival of this species decreased from $40.0 \pm 10.0 \%$ under control to $20.0 \pm 5.0 \%$ under future conditions.

\section{Length and growth}


260 The mean standard length of newly-hatched larvae (at $0 \mathrm{dph}$ ) was independent of the treatment (Fig. 2A,B), with no terms found to be significant $(p=0.284, p=0.982$ and $\mathrm{p}=0.393$ for temperature, $p \mathrm{CO}_{2}$ and the interaction between both factors, respectively). Size at hatching ranged between $2.6 \pm 0.2$ and $2.7 \pm 0.3 \mathrm{~mm}$ for $S$. aurata, and between $2.5 \pm 0.5$ and $2.7 \pm 0.3 \mathrm{~mm}$ for $A$. regius. Considering growth (Fig. $2 \mathrm{C}, \mathrm{D})$, the main effect of $p \mathrm{CO}_{2}$ was significant $(\beta=-0.028, \mathrm{SE}=0.008, \mathrm{p}=0.009)$, as well as the interaction between $p \mathrm{CO}_{2}$ and species $(\beta=0.037, \mathrm{SE}=0.012, \mathrm{p}=0.003)$. However, neither temperature $(p=0.098)$ nor species $(p=0.107)$ had a significant effect. SLG was higher for $A$. regius, with values ranging from 0.09 to $0.11 \mathrm{~mm}^{-}$day1 , while for $S$. aurata it ranged from 0.06 to $0.09 \mathrm{~mm} \mathrm{day}^{-1}$. The significant interaction between $p \mathrm{CO}_{2}$ and species arises from the fact that growth was higher under normocapnia for $S$. aurata but higher under hypercapnia for A. regius.

\section{Body malformations}

Malformations were only assessed for S. aurata (Figs. 3 and 4). Regarding total malformations (Fig. 4A), both the main effects temperature $(\beta=0.946, S E=0.328$, $\mathrm{p}=0.004)$ and $\mathrm{CCO}_{2} \quad(\beta=1.730, \mathrm{SE}=0.332, \mathrm{p}<0.01)$ were significant, but the interaction between both factors was not $(p=0.287)$. The odds of total malformations under warming were 2.57 (95\% CI: 1.35, 4.90) times the odds of malformations under control temperature, while the odds under hypercapnia were $5.64(95 \% \mathrm{CI}: 2.95,10.80)$ times the odds under normocapnia. The incidence of malformations increased from $25.00 \pm 13.23 \%$ under control conditions to $81.67 \pm 10.41 \%$ under the warmer and acidified scenario. The only term included in the cranium malformations model was $p \mathrm{CO}_{2}(\beta=1.704 \mathrm{SE}=4.272, \mathrm{p}<0.001)$, with a higher proportion of malformations observed under hypercapnia (Fig. 4B). Neither temperature $(p=0.729)$ nor the interaction between both factors $(p=0.166)$ was significant. The odds under hypercapnia were 5.50 (95\% CI: 2.52, 12.02) times the odds under normocapnia. Under elevated $p \mathrm{CO}_{2}$, the incidence of cranium malformations increased significantly from $8.33 \pm 2.88$ to $21.67 \pm 2.87 \%$ under control temperature, and from $6.67 \pm 2.89$ to $40.00 \pm 5.00 \%$ under warming. With respect to abdominal malformations (Fig. 4C), none of the variables was significant $\left(\mathrm{p}=0.232, \mathrm{p}=0.232\right.$ and $\mathrm{p}=0.539$ for temperature, $p \mathrm{CO}_{2}$ and the interaction between 
293 both factors, respectively). For caudal malformations (Fig. 4D), there was not

enough information to build a model, since this type of malformation was only observed in one of the four treatments. However, a great proportion $(26.7 \pm 2.9 \%)$ of the fish in the warmer and acidified scenario presented this malformation.

\section{Behavioural patterns}

In terms of behaviour (Fig. 5), a model was considered for each species. For $S$. aurata, swimming (Fig. 5A) was only significantly affected by $p \mathrm{CO}_{2}(\beta=-18.333$, $\mathrm{SE}=2.590, \mathrm{p}<0.001)$, and not by temperature $(\mathrm{p}=0.164)$. Additionally, no significant interaction was found between both factors $(\mathrm{p}=0.243)$. Swimming duration significantly decreased with $\mathrm{pCO}_{2}$ from $47.6 \pm 6.3$ to $32.5 \pm 6.1$ sec at normal temperature, and from $53.2 \pm 12.4$ to $31.6 \pm 9.4 \mathrm{sec}$ at the warming condition. For attack (Fig. 5C), both temperature $(\beta=0.352, \mathrm{SE}=0.163, \mathrm{p}=0.031)$ and $p \mathrm{CO}_{2}(\beta=-$ 1.214, SE=0.261, $\mathrm{p}<0.001$ ) were found significant, as well as the corresponding interaction $(\beta=0.862, S E=0.308, p=0.005)$. More attacks happened under higher temperatures, but this increase was more pronounced under hypercapnia than normocapnia. The capture success (Fig. 5E) was also significantly affected by $p \mathrm{CO}_{2}$ $(\beta=-1.466, S E=0.320, p=0.000)$, but not by temperature $(p=0.145)$. Moreover, the interaction between both factors $(\beta=0.802, \mathrm{SE}=0.382, \mathrm{p}=0.036)$ was also significant. The capture success of this species decreased significantly under hypercapnic conditions, from $4.3 \pm 1.7$ to $1.0 \pm 0.4 \%$ under control temperature, and from $5.7 \pm 1.4$ to $3.0 \pm 0.9 \%$ at warmer temperatures. For spin behaviour (Fig. $5 \mathrm{G}$ ), there was not enough information to build the model because this behaviour was only observed under warming and hypercapnic conditions.

Regarding A. regius, swimming (Fig. 5B) was significantly affected by temperature $(\beta=8.750, \mathrm{SE}=1.817, \mathrm{p}=0.001)$ and $p \mathrm{CO}_{2}(\beta=-10.917, \mathrm{SE}=1.817, \mathrm{p}=0.000)$, but no significant interaction was found between factors $(\mathrm{p}=0.627)$. Warmer temperature significantly increased the time larvae spent swimming from $40.1 \pm 5$.6 to $49.7 \pm 4.4$ sec under normocapnia, and from $30.1 \pm 5.8$ to $37.9 \pm 5.1$ sec under hypercapnia. In contrast, swimming duration significantly decreased with $p \mathrm{CO}_{2}$, from $40.1 \pm 5.6$ to $30.1 \pm 5.8 \mathrm{sec}$ at normal temperature, and from $49.7 \pm 4.4$ to $37.9 \pm 5.1 \mathrm{sec}$ at the warming condition. The attack (Fig. 5D) and capture rates (Fig. 5F) were only 
326 significantly affected by $\mathrm{CO}_{2}(\beta=-0.367, \mathrm{SE}=0.146, \mathrm{p}=0.012$ and $\beta=-0.693$, $327 \mathrm{SE}=0.158, p<0.001$, respectively). Neither the effect of temperature $(p=0.250)$ nor 328 the interaction $(\mathrm{p}=0.459)$ was significant. Attack rates decreased significantly with $329 \mathrm{pCO}_{2}$ from $5.3 \pm 2.7$ to $1.6 \pm 0.9 \%$ at control temperature, and from $7.6 \pm 2.1$ to $3305.3 \pm 2.0 \%$ at warming. The capture success also decreased significantly with acidification from $4.8 \pm 2.7$ to $2.1 \pm 0.8 \%$ under present-day temperature, and from $5.2 \pm 2.4$ to $2.9 \pm 1.4 \%$ under warming. No spin behaviour was observed for this species (Fig. 5H).

\section{Discussion}

In the present study, we showed that early life stages of $S$. aurata and A. regius were quite sensitive to future ocean conditions. Both warming and acidification significantly lowered the hatching and survival rates of both species. In comparison to the present day scenario, the survival of $15 \mathrm{dph}$ seabream and 10 dph meagre decreased by half under future warming and acidified conditions. The standard length of newly-hatched larvae was not significantly affected, but hypercapnia had a significant effect on larval growth. However, while the SLG of $S$. aurata showed a 24.8-36.4\% decrease under hypercapnic conditions, a slight increase (3.2-12.9\%) was observed in A. regius. The former results may suggest a weak control and maintenance of internal $\mathrm{pH}$ on $S$. aurata and a consequent decrease in protein biosynthesis (Langenbuch and Pörtner 2003). In this species, the energy budget may have been allocated away from non-essential processes, such as growth, towards maintenance (Pörtner and Peck 2010). The present difference observed between species reinforces the absence of consensus among studies on the effect of ocean acidification on the size and growth of marine fish larvae. While some studies have reported decreased size and growth under high $p \mathrm{CO}_{2}$ levels (Baumann et al. 2012; Frommel et al. 2014; Pimentel et al. 2014), others indicate that larvae may grow equally well or even faster under high $p \mathrm{CO}_{2}$ conditions (Hurst et al. 2013; Hurst et al. 2012; Schade et al. 2014). If the impact on growth is truly species-specific, then ocean acidification and warming may have a complex impact on the dynamics of marine food webs, since larval growth and body size can mediate susceptibility to predation mortality (Anderson 1988). 
359 Nonetheless, we can also argue that such contradictory findings may be the result 360 of experiments being carried out at temperatures with unclear positioning on 361 thermal performance curves, or possibly due to experimental rearing artefacts (e.g.

362 363 364 365 366 367 368 369 370 different feeding regimes). It is worth noting that our findings on survival and growth under present-day conditions were quite similar to those found in the literature for these species under intensive rearing conditions (Papandroulakis et al. 2000; Roo et al. 2010).

Ocean warming and acidification also had a significant effect on the incidence of malformations, with the exception of abdominal malformations. At present-day conditions, the formation pattern of the axial skeleton elements in S. aurata was similar to that reported for other teleost larvae (Sfakianakis et al. 2004). Under the combined effect of hypercapnia and warming, the incidence of malformations greatly increased. The incidence of total malformations was more than 3 times higher under future warming and acidified conditions than when compared to present-day conditions. Cranium malformations also increased significantly with ocean acidification. Under the future scenario, the occurrence of this malformation was 31.7 percentage points higher than in present-day conditions. Although there was not enough information to build a model for caudal axial deviations, it has to be noticed that almost $30 \%$ of the fish presented this malformation when exposed to the combined effect of warming and acidification. Other studies also found greater incidence of abnormal development in fish larvae under elevated temperature and/or $p \mathrm{CO}_{2}$ (Baumann et al. 2012; Pimentel et al. 2014; Ahnelt et al. 2015). During early development, axial deviations may result from defective development of the notochord and perinotochordal connective sheet (Sanatamaría et al. 2005), which can in turn lead to further skeletal malformations in the vertebral column such as lordosis, scoliosis and kyphosis. We argue that such malformations may affect the larval capacity to maintain the position in the water column, and further compromise their swimming, foraging and predator avoidance (Powell et al. 2009).

In the present study, larval behaviour was affected by future ocean conditions. Temperature increased the time $A$. regius larvae spent swimming, but did not affect S. aurata swimming. In contrast, hypercapnia decreased the time spent swimming in both species. Interestingly, S. aurata larvae showed an erratic "spin" movement 
392 only at higher temperatures and $\mathrm{pCO}_{2}$ levels. Even though some previous studies 393 have found no effect of ocean acidification on fish swimming behaviour (e.g. 394 Maneja et al. 2013a), others have reported significant changes in this behaviour 395 under such environmental conditions (e.g. Dixson et al. 2010; Munday et al. 2010). 396 Reduced swimming skills and the occurrence of erratic movements by the larvae in 397 the wild may potentially affect their vulnerability to predation. Moreover, 398 hypercapnia also decreased the attack and capture rates of prey. The lower 399 capture success of prey will most certainly impact their growth and development, 400 and further affect larval performance, survival and recruitment rates (Stanley 401 2009). It is however important to keep in mind that some bias may potentially arise from the effects that ocean changes might have on live prey and larvae-prey 403 interaction, which directly affects food availability and fish larval behaviour. In conclusion, the biological responses of $S$. aurata and $A$. regius larvae presented in the present study provide an insight of how future warming and acidification may impact the development of wild fish larvae and their fitness in a changing ocean. However, results should be carefully interpreted, given the reduced genetic variability that may arise from a limited number of spawners. Moreover, given the time frame in which ocean warming and acidification are expected to occur, it is important not to forget that there will be an opportunity for acclimatization and adaptation. Although the mechanisms for adaptation remain poorly known, some studies have already shown that parental (transgenerational) acclimation can modify the response of fish larvae to climate change conditions (e.g. Schade et al. 2014; Welch et al. 2014). It is therefore expected that such processes can moderate the negative impacts of future ocean conditions on $S$. aurata and $A$. regius larvae. Future efforts should focus on how these environmental factors may affect commercially important fish species at higher levels of organization (e.g. at a population-level) in a way to help managers and policy-makers to take proactive

\section{Acknowledgements}

We thank Maresa and CRIPSul for supplying fish eggs, and LusoReef, Oceanário de Lisboa and Aquário Vasco da Gama for supplying rotifers and microalgae. 


\section{Author contributions}

426 R.R. and M.S.P. designed the experiment; M.S.P. and G.D. performed the 427 experiments; M.S.P., F.F., T.M., R.B., G.D., J.M., P.P.F. and R.R. analysed the data; 428 M.S.P., F.F., T.M., R.B., G.D., A.M.F., J.M., M.P., H.P., E.J.G. and R.R. wrote the main 429 paper. All authors discussed the results and their implications, and commented on 430 the manuscript at all stages.

431

432 Funding

433 The Portuguese Foundation for Science and Technology (FCT) supported this 434 study through doctoral grants to M.S.P. and G.D. (SFRH/BD/81928/2011 and 435 SFRH/BD/73205/2010, respectively), a post-doc grant to F.F. 436 (SFRH/BPD/79038/2011), and project grants to P.P.F. (AQUACOR-PROMAR31-03437 05FEP-003) and R.R. (PTDC/MAR/0908066/2008 and 438 PTDC/AAGGLO/3342/2012). 


\section{References}

Ahnelt H, Schade FM, Wegner M (2015) Ocean acidification leads to deformations of caudal vein angio-architecture in juvenile threespine stickleback, Gasterosteus aculeatus Linnaeus. J. Fish Dis.

Anderson JT (1988) A review of size dependent survival during pre-recruit stages of fishes in relation to recruitment. J. Northwest Atl. Fish. Sci. 8:5566

Arias A (1980) Crecimiento, regimen alimentario y reproducción de la dorada (Sparus aurata L.) y del robalo (Dicentrarchus labrax L.) en los esteros de Cadiz. Invest. Pesq. 44:59-83

Baumann H, Talmage SC, Gobler CJ (2012) Reduced early life growth and survival in a fish in direct response to increased carbon dioxide. Nature Clim. Change 2:38-41

Barr DJ, Levy R, Scheepers C, Tily HJ (2013) Random effects structure for confirmatory hypothesis testing: Keep it maximal. J. Mem. Lang 68: 255278

Boglione C, Gagliardi F, Scardi M, Cataudella S (2001) Skeletal descriptors and quality assessment in larvae and post-larvae of wild-caught and hatcheryreared gilthead sea bream (Sparus aurata L. 1758). Aquaculture 192:1-22

Bromhead D, Scholey V, Nicol S, Margulies D, Wexler J, Stein M, Hoyle S, LennertCody C, Williamson J, Havenhand J, Ilyina T, Lehodey P (2015) The potential impact of ocean acidification upon eggs and larvae of yellowfin tuna (Thunnus albacares). Deep Sea Res. Part II 113:268-279

Collins M, Knutti R, Arblaster J, Dufresne J-L and others (2013) Long-term climate change: projections, commitments and irreversibility. In: Stocker TF, Qin D, Plattner G-K, Tignor M and others (eds) Climate Change 2013: The Physical Science Basis. Cambridge University Press Cambridge, United Kingdom, and New York, USA

Dickson A, Millero F (1987). A comparison of the equilibrium constants for the dissociation of carbonic acid in seawater media. Deep Sea Res. A 34:17331743

Dixson DL, Munday PL, Jones GP (2010) Ocean acidification disrupts the innate 
ability of fish to detect predator olfactory cues. Ecology Letters 13:68-75

Drost M (1987) Relation between aiming and catch success in larval fish. Can. J. Fish Aquat. Sci. 44:304-315

Fernández I, Hontoria F, Ortiz-Delgado JB, Kotzamanis Y, Estévez A, ZamboninoInfante JL, Gisbert E (2008) Larval performance and skeletal deformities in farmed gilthead sea bream (Sparus aurata) fed with graded levels of Vitamin A enriched rotifers (Brachionus plicatilis). Aquaculture 283:10115

Frommel A, Maneja F, Lowe D, Pascoe C, Geffen A, Folkvord A, Piatkowski U, Clemmensen C (2014) Organ damage in Atlantic herring larvae as a result of ocean acidification. Ecol. App. 24:1131-1143

Harvey BP, Gwynn-Jones D, Moore PJ (2013) Meta-analysis reveals complex marine biological responses to the interactive effects of ocean acidification and warming. Ecol.Evol. 3:1016-1030

Hurst TP, Fernandez ER, Mathis JT (2013) Effects of ocean acidification on hatch size and larval growth of walleye pollock (Theragra chalcogramma). Ices J. Mar. Sci. 70:812-822

Hurst TP, Fernandez ER, Mathis JT, Miller JA, Stinson CM, Ahgeak EF (2012) Resiliency of juvenile walleye pollock to projected levels of ocean acidification. Aquatic Biol. 17:247-259

Langenbuch M, Pörtner H (2003) Energy budget if hepatocystes from Antartic fish (Pachycara brachycephalum and Lepidonotothen kempi) as a function of ambient $\mathrm{CO}_{2}: \mathrm{pH}$-dependent limitations of cellular protein biosynthesis? J. Exp. Biol. 206:3895-3903

Lewis E, Wallace DWR (1998) CO2SYS-Program developed for the CO2 system calculations. Carbon Dioxide Inf Anal Center, Report ORNL/CDIAC-105

Maneja RH, Frommel AY, Browman HI, Clemmesen C, Geffen AJ, Folkvord A, Piatkowski U, Durif CMF, Bjelland R, Skiftesvik AB (2013a) The swimming kinematics of larval Atlantic cod, Gadus morhua L., are resilient to elevated seawater $p \mathrm{CO}_{2}$. Mar. Biol.

Maneja RH, Frommel AY, Geffen AJ, Folkvord A, Piatkowski U, Chang MY, Clemmesen C (2013b) Effects of ocean acidification on the calcification of 
otoliths of larval Atlantic cod Gadus morhua. Mar. Ecol. Prog. Ser. 477:251-258

Melzner F, Gutowska MA, Langenbuch M, Dupont S, Lucassen M, Thorndyke MC, Bleich M, Portner HO (2009) Physiological basis for high CO2 tolerance in marine ectothermic animals: pre-adaptation through lifestyle and ontogeny? Biogeosciences 6:2313-2331

Mehrbach C, Culberson C, Hawley J, Pytkowicz R (1973) Measurement of the apparent dissociation constants of carbonic acid in seawater at atmospheric pressure. Limnol. Oceanogr. 18:897-907

Munday PL, Hernaman V, Dixson DL, Thorrold SR (2011) Effect of ocean acidification on otolith development in larvae of a tropical marine fish. Biogeosciences 8:1631-1641

Papandroulakis N, Markakis G, Divanach P, Kentouri M (2000) Feeding requirements of sea bream (Sparus aurata) larvae under intensive rearing conditions: Development of a fuzzy logic controller for feeding. Aquacult. Eng. 21:285-299

Peck M, Huebert K, Llopiz J (2012) Intrinsic and extrinsic factors driving matchmismatch dynamics during the early life history of marine fishes. Adv. Ecol. Res. 47:177-302

Pimentel MS, Faleiro F, Dionísio G, Repolho T, Pousão-Ferreira P, Machado J, Rosa R (2014) Defective skeletogenesis and oversized otoliths in fish early stages in a changing ocean. J. Exp. Biol. 217:2062-2070

Pörtner HO, Langenbuch M, Michaelidis B (2005) Synergistic effects of temperature extremes, hypoxia, and increases in $\mathrm{CO} 2$ on marine animals: From Earth history to global change. J. Geophys. Res. Oceans. 110:C09S10

Pörtner HO, Langenbuch M, Reipschlager A (2004) Biological impact of elevated ocean CO2 concentrations: Lessons from animal physiology and earth history. J. Ocean. 60:705-718

Pörtner HO, Peck MA (2010) Climate change effects on fishes and fisheries: towards a cause-and-effect understanding. J. Fish Biol. 77:1745-1779

Pousão-Ferreira P, Castanho S, Ribeiro L, Coutinho J, Bandarra NM, Mendes AC Larval rearing protocols for meagre Agyrosomus regius in LARVI'13 - Fish \& shellfish larviculture symposium, Commun. Agric. Appl. Biol. Sci., 
Laboratory of aquaculture \& artemia reference center, Ghent University, Belgium., pp. 378-381

Powell MD, Jones MA, Lijalad M (2009) Effects of skeletal deformities on swimming performance and recovery from exhaustive exercise in triploid Atlantic salmon. Dis. Aquat. Org. 85:59-66

Quéro JC, Vayne JJ (1987) Le maigre, Argyrosomus regius (Asso, 1801) (Pisces, perciformes, sciaenidae) du golfe de Gascogne et des eaux plus septentrionales. Rev. Trav. Inst. Pêches Marit. 19 (1985):35-66

Ronnegard L, Shen $\mathrm{X}$, Alam M hglm: A Package for Fitting Hierarchical Generalized Linear Models The R Journal. 2:20-28

Roo J, Hernández-Cruz CM, Borrero C, Schuchardt D, Fernández-Palacios H (2010) Effect of larval density and feeding sequence on meagre (Argyrosomus regius; Asso, 1801) larval rearing. Aquaculture 302:82-88

Sanatamaría JA, Andrades JA, Herráez P, Fernández-Llebrez P, Becerra J (2005) Perinotochordal connective sheet of gilthead sea bream larvae (Sparus aurata, L.) affected by axial malformations: An histochemical and immunocytochemical study. Dev. Biol. 240:248-254

Sarazin G, Michard G, Prevot F (1999) A rapid and accurate spectroscopic method for alkalinity measurements in sea water samples. Water Res. $33: 290-294$

Schade FM, Clemmensen C, Wegner KM (2014) Within- and transgenerational effects of ocean acidification on life history of marine three-spined stickleback (Gasterosteus aculeatus). Mar. Biol. 161:1667-1676

Sfakianakis DG, Koumoundouros G, Divanach P, Kentouri M (2004) Osteological development of the vertebral column and of the fins in Pagellus erythrinus (L. 1758). Temperature effect on the developmental plasticity and morpho-anatomical abnormalities. Aquaculture 232:407-424

Stanley RRE (2009) A biophysical study of connectivity in the early life history of coastal Newfoundland fishes. Memorial University of Newfoundland, St. John's 
Welch MJ, Watson S, Welsh JQ, McCormick MI, Munday PL (2014) Effects of elevated $\mathrm{CO} 2$ on fish behaviour undiminished by transgenerational acclimation. Nature Clim. Change | Letter 4:1086-1089

Wittmann AC, Pörtner HO (2013) Sensitivities of extant animal taxa to ocean acidification. Nature climate change 3:995-1001

Zuur AF, Ieno EN, Walker N, Saveliev AA, Smith GM (2009) Mixed Effects Models And Extensions In Ecology With R. Springer, New York 
Figure 1

Sparus aurata

A

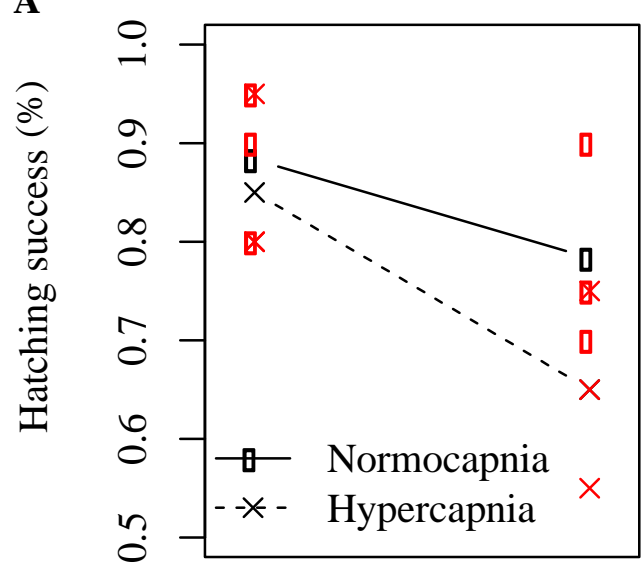

C

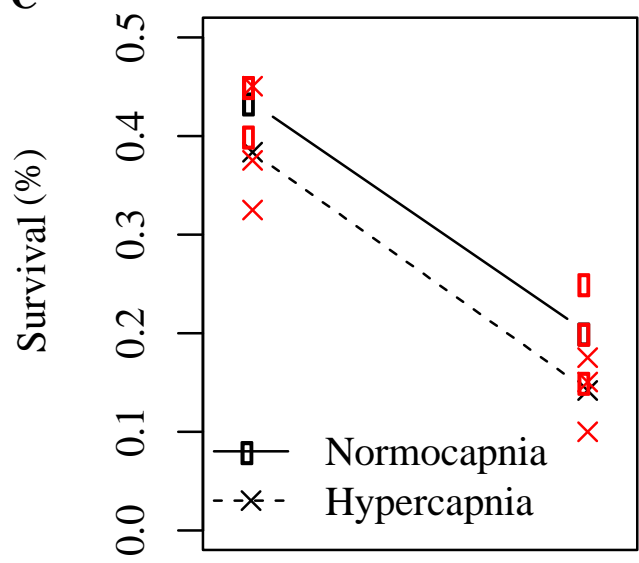

T1

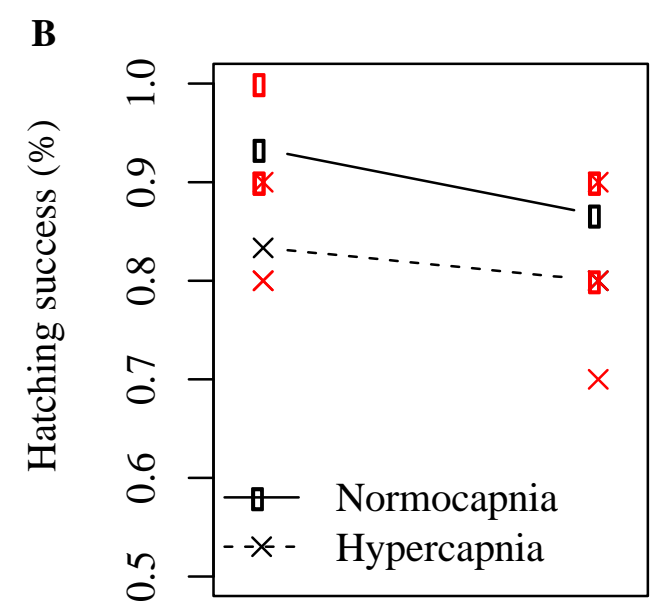

D

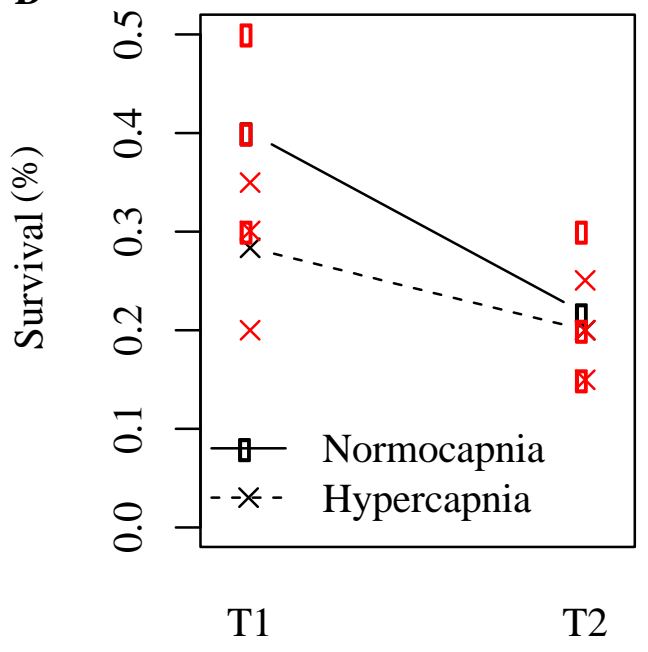

Temperature

Argyrosomus regius

Temperature 
Figure 2
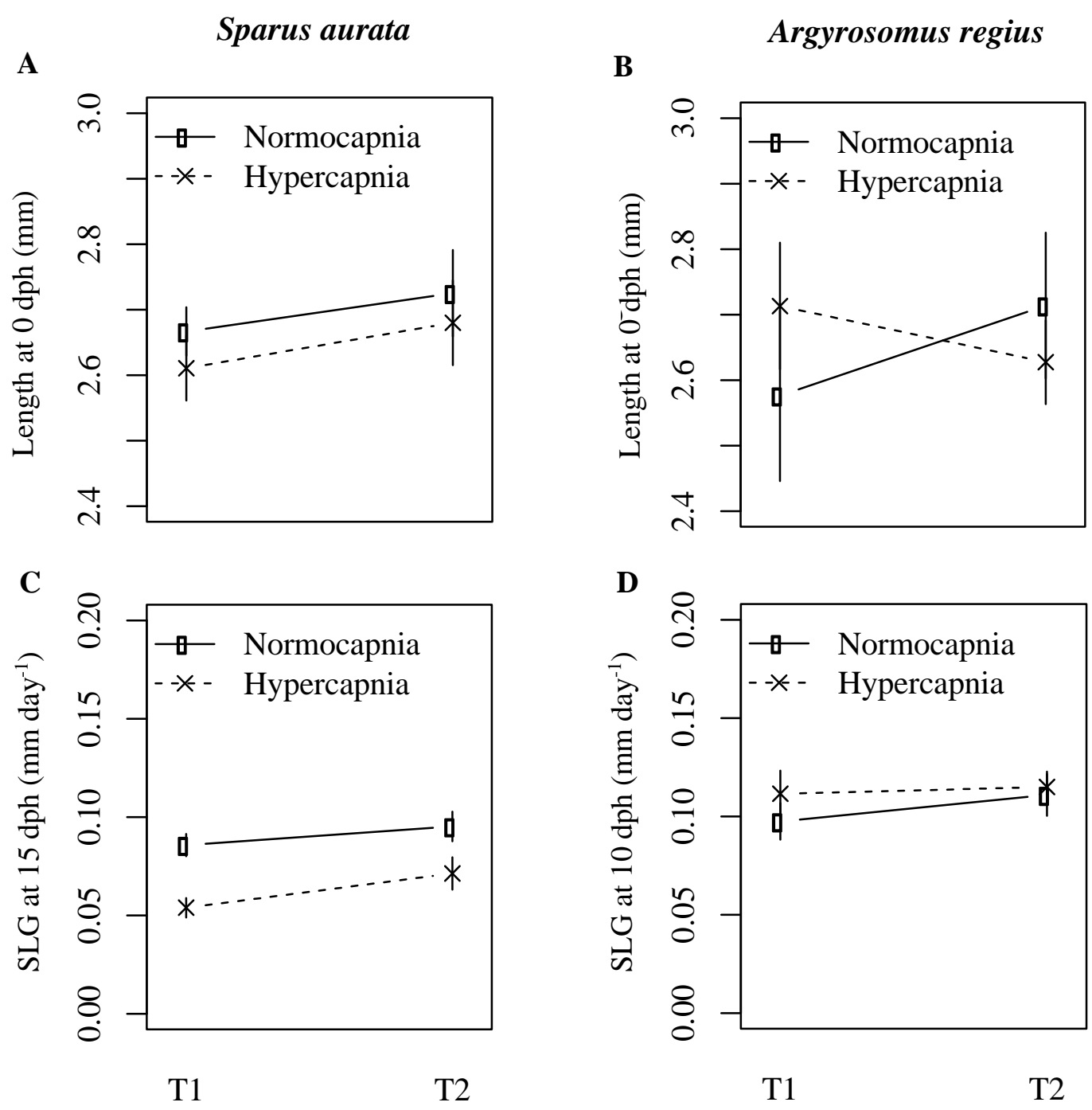

Temperature

Temperature 
Figure 3

A

B
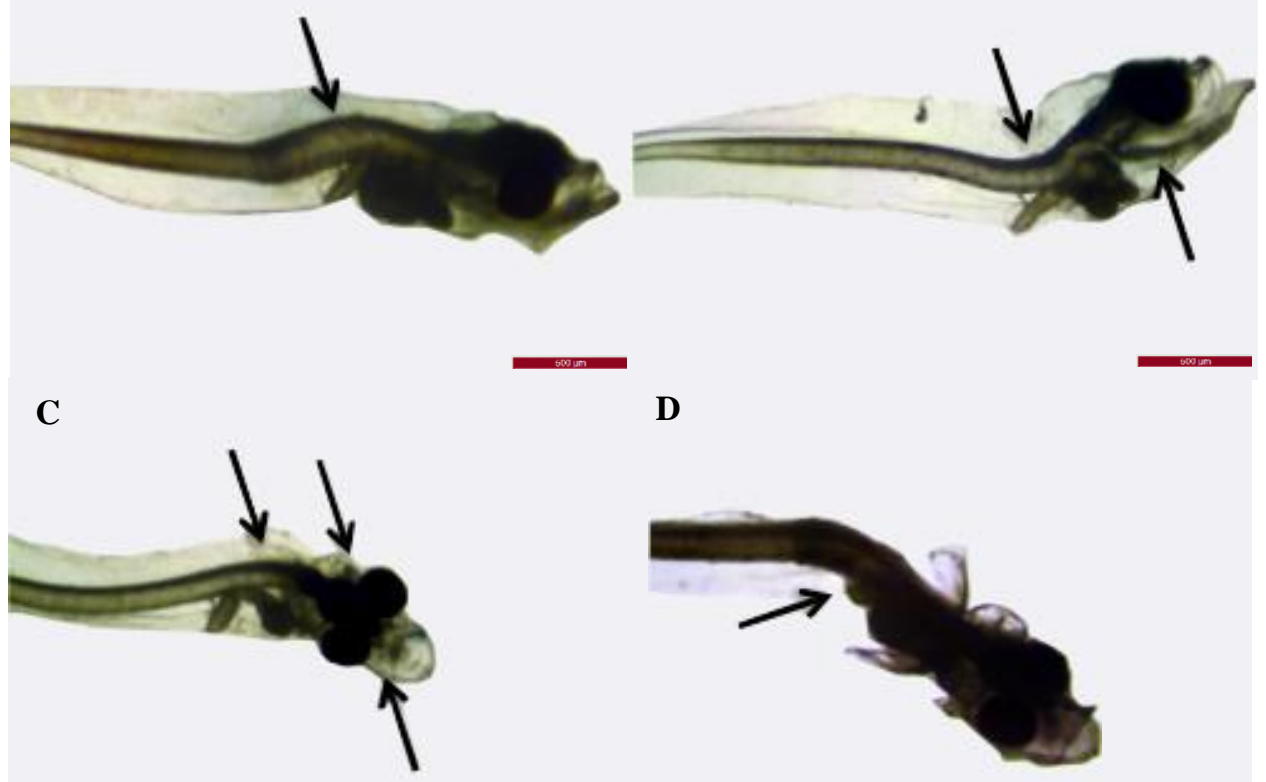

E
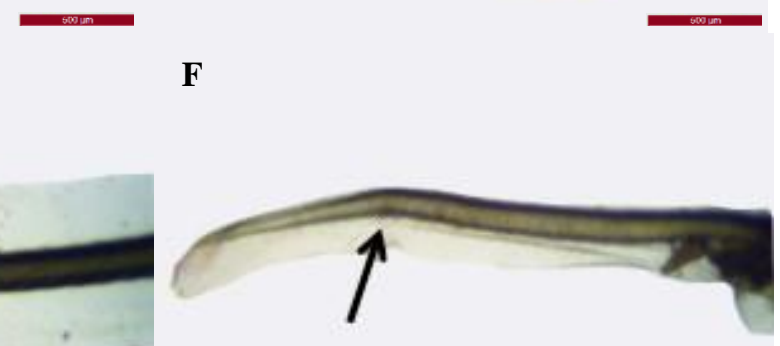

G

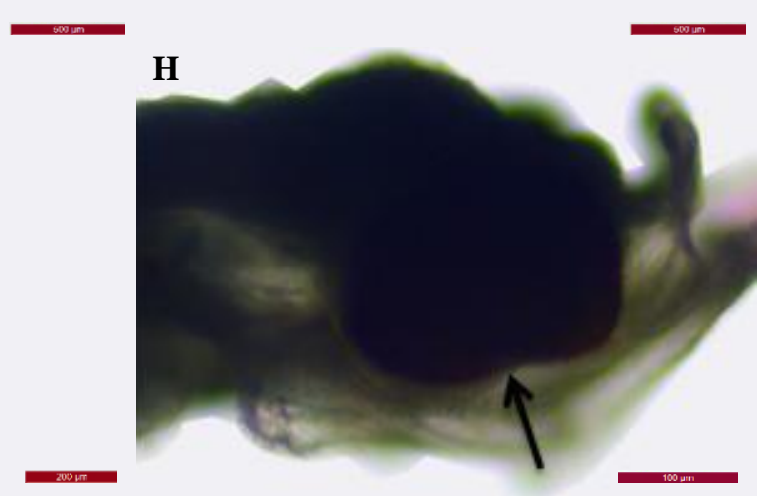




\section{Figure 4}

A

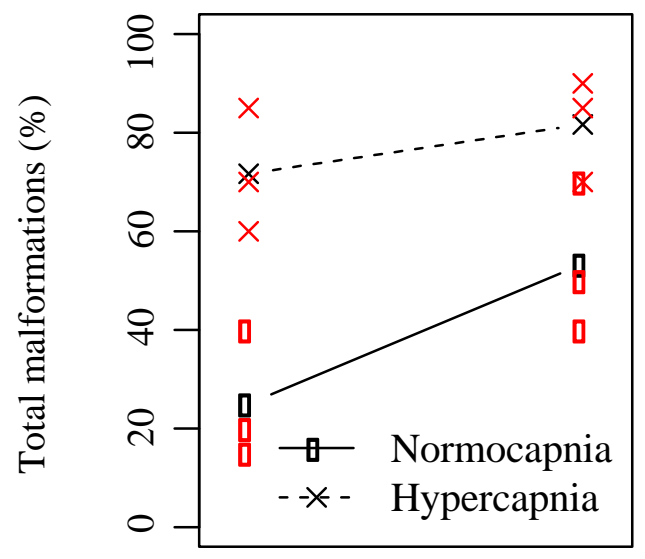

C

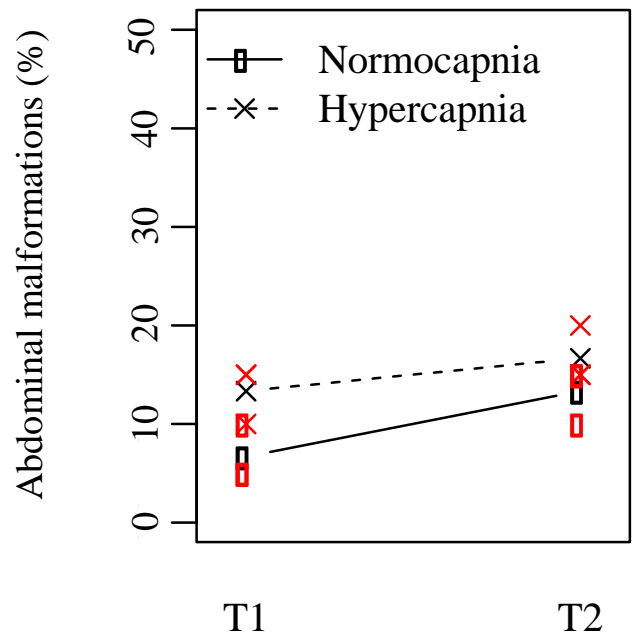

Temperature
B

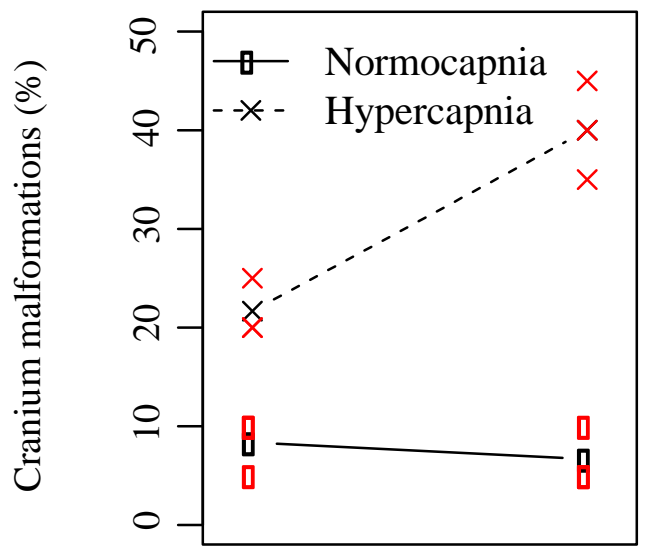

D

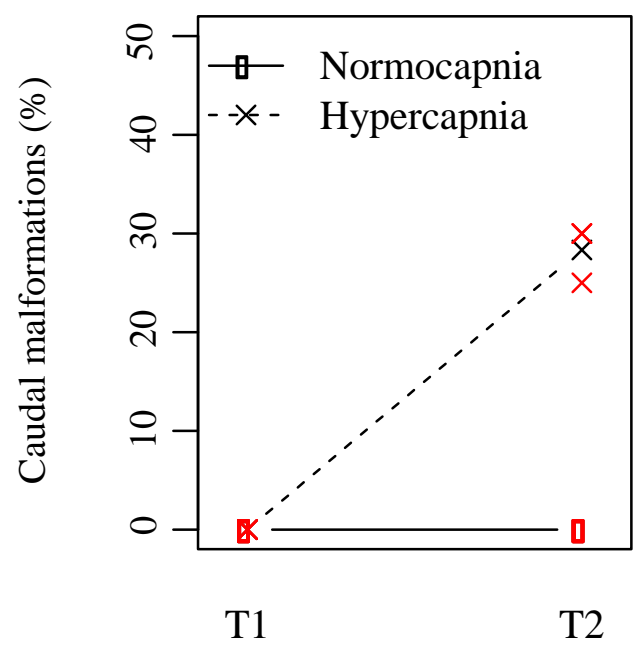

Temperature 
Figure 5

Sparus aurata

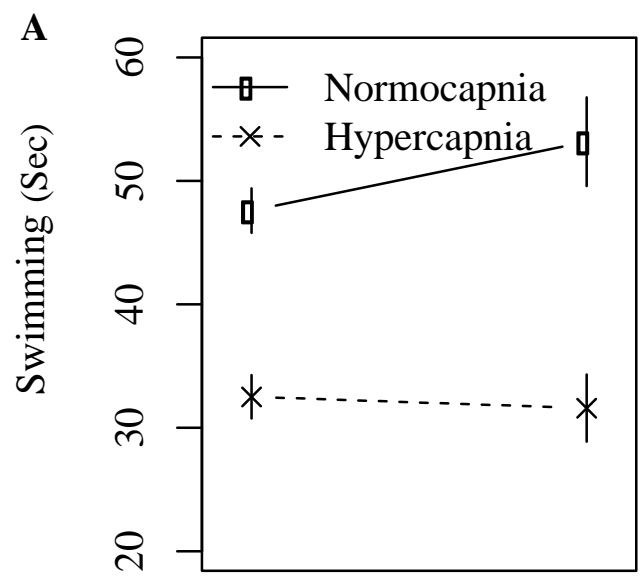

C

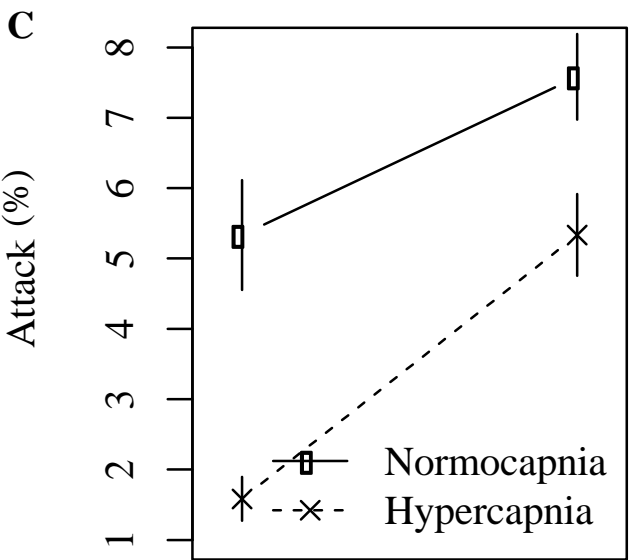

E

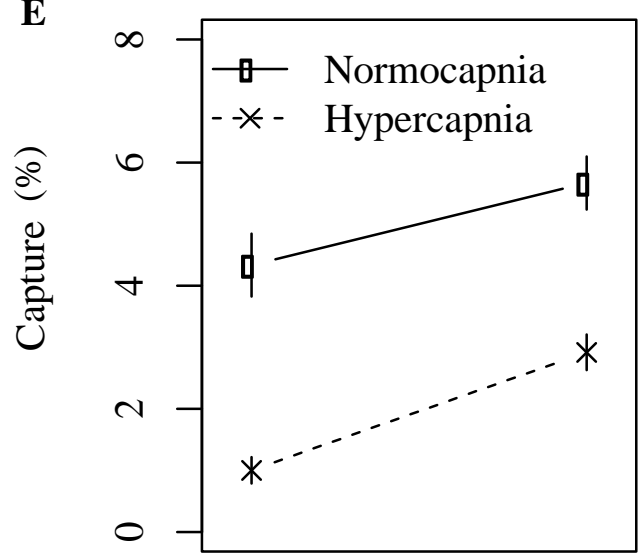

G

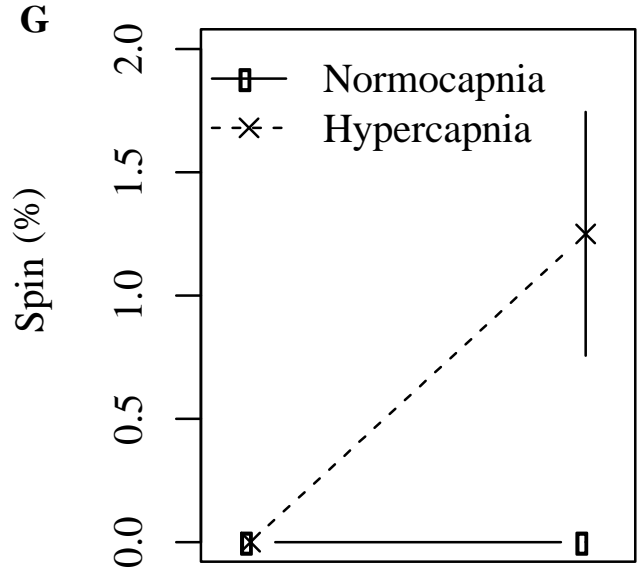

T1
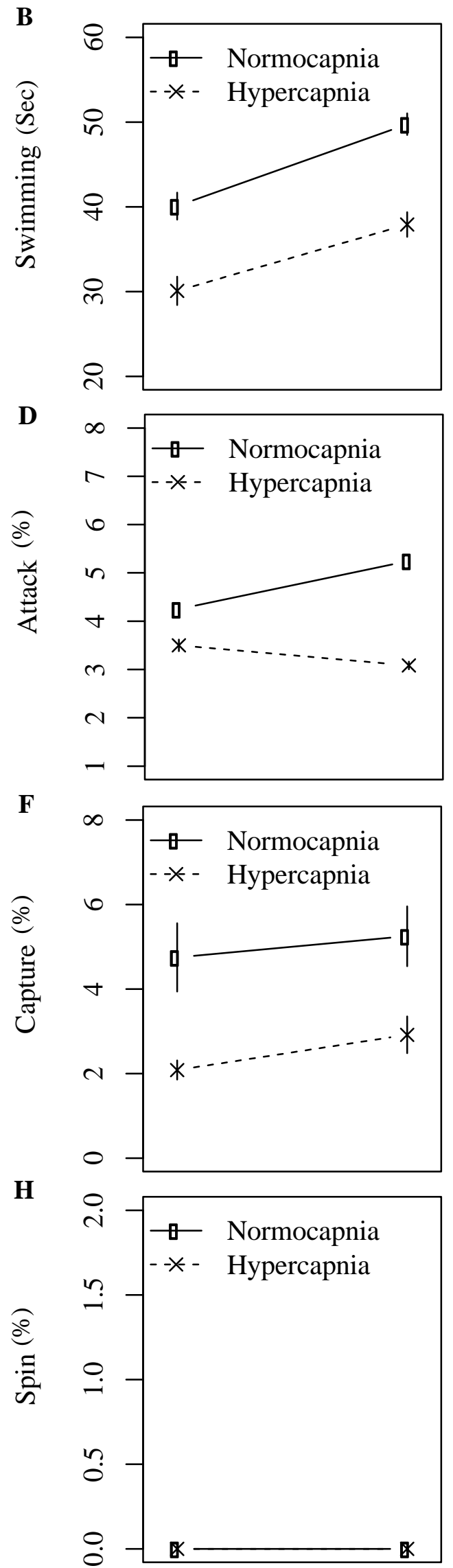

T1 